\title{
Desporto aventura e auto-estima nos adolescentes, em meio escolar
}

\author{
Rui P.S. Bernardo \\ Margarida G. Matos
}

https://doi.org/10.5628/rpcd.03.01.33

\section{RESUMO}

O desenvolvimento de programas adequados de actividade física e desportiva pode melhorar o bem-estar psicológico e reduzir o risco de determinados problemas de saúde. Atendendo a que a auto-estima tem ocupado consistentemente uma posição central na explicação do comportamento humano, foi objectivo deste estudo avaliar os efeitos de um Programa de Desporto Aventura na auto-estima e nas auto-percepções físicas de jovens participantes $(n=38)$. O instrumento utilizado para a avaliação da auto-estima e auto-percepções físicas foi uma versão traduzida do Physical Self-Perception Profile for Children and Youth (33). Como principais conclusões deste estudo pode referir-se que os participantes reportaram, após o programa, valores médios mais elevados na sua auto-estima, nas suas auto-percepções físicas e na importância a estas atribuída. No sentido da confirmação dos resultados do presente estudo, sugere-se a realização de mais investigações neste domínio.

Palavras-chave: auto-estima, auto-estima física, auto-percepções físicas, actividade física e desportiva, desporto aventura, Physical Self-Perception Profile for Children and Youth (PSPP-CY).

\author{
Faculdade de Motricidade Humana \\ Universidade Técnica de Lisboa, Portugal
}

\begin{abstract}
uutaoor aaventure actıvitıes ana selj-esteem in aaolescent students

The development of sport and physical activity programs may improve psychological well-being and reduce risk factors of several health problems. Self-esteem has shown to have a strong position in the explanation of human behaviour. The purpose of this study was to evaluate the effects of an Outdoor Adventure Activities Program on the self-esteem and physical self-perceptions of Portuguese school adolescents $(n=38)$. A translated version of the Physical Self-Perception Profile for Children and Youth (PSPP-CY) was used to assess self-esteem and physical selfperceptions. The main conclusions of this study showed that participants in general reported higher values on their self-esteem and physical self-perceptions after the program. Further experimental programs are required to confirm the results of this study.
\end{abstract}

Key Words: self-esteem, physical self-worth, physical self-perceptions, sports and physical activity, outdoor adventure activities, Physical SelfPerception Profile for Children and Youth (PSPP-CY) 


\section{INTRODUÇÃO}

Parece existir um consenso emergente na comunidade científica acerca da definição dos constructos "auto-estima" e "auto-conceito". Segundo diversos autores (e.g. 6, 29, 32) o auto-conceito consiste nas percepções que o indivíduo tem de si mesmo, ou seja, corresponde à sua auto-descrição, contribuindo para a construção da imagem multifacetada que cada indivíduo tem de si próprio, enquanto que a auto-estima é a avaliação ou o sentimento do indivíduo acerca da sua imagem (e.g. 1, 10, 18), isto é, implica um grau de satisfação, ou insatisfação, consigo próprio.

Durante muitos anos os investigadores avaliaram a auto-estima como uma medida global sem atenderem às diferentes percepções do self que compõem este constructo (28). A avaliação destes estudos revelou que as conclusões reflectiam problemas de mensuração e de análise estatística que não suportavam a unidimensionalidade do auto-conceito e da auto-estima (21). A evidência científica suportada por inúmeros estudos veio alterar esta visão global ou unidimensional como factor explicativo dos aspectos do self, parecendo não haver qualquer suporte para a perspectiva unidimensional do auto-conceito e da auto-estima (9, 21). A crença de que os indivíduos podem ter um elevado número de diferentes auto-percepções em aspectos separados das suas vidas levou à aceitação do self como uma realidade multidimensional. A fase contemporânea do estudo da auto-estima tem início quando o enfoque se passa a centrar directamente nos mecanismos da mudança envolvidos no sistema do self (8), como acontece no caso dos modelos hierárquicos multidimensionais. A partir dos anos 80 , com o progresso registado na avaliação da auto-estima (9), ficou mais claro que para compreender completamente a natureza e conteúdo da auto-estima de um indivíduo é necessário aceder às suas auto-percepções em diferentes domínios da vida. Os modelos hierárquicos multidimensionais da auto-estima sugerem que as auto-avaliações em domínios específicos estão de algum modo agregadas para formar a auto-estima global. Neste sentido, o self físico tem ocupado uma posição única no sistema do self, porque o corpo, através da sua aparência, atributos e capacidades, providencia um substantivo interface entre o indivíduo e o mundo que o rodeia (11). Pesquisas neste domínio (e.g. 13) têm enfatizado a auto-estima física como um constructo multidimensional e hierárquico, fazendo parte da auto-estima global. Fox (6, 7) e Fox e Corbin (13) sugerem um modelo hierárquico multidimensional da auto-estima que sustenta que existe um nível global de auto-estima relativamente estável e alto no cume, que é o resultado de percepções avaliativas em vários domínios da vida, como sejam o académico, o social, o emocional ou o físico (Figura 1). Cada domínio considerado representa os efeitos combinados de percepções de um nível inferior de hierarquia, pelo que, à medida que se desce na hierarquia, a estabilidade diminui e as facetas tornam-se cada vez mais fraccionadas e específicas de uma dada situação. No modelo apresentado pelos autores, no caso da auto-estima física (Figura 2 ), considera-se que esta depende de quatro dimensões: competência desportiva, corpo atraente, força física e condição física. Este modelo é particularmente atractivo, uma vez que sugere um mecanismo testável, no qual os constructos globais, ainda que mais estáveis e duradouros, estão abertos a modificações eventuais através de mudanças das auto-percepções em níveis inferiores.

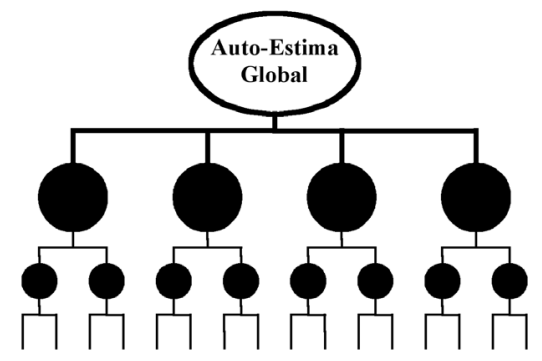

Figura 1. Modelo hierárquico da estrutura da auto-estima [adaptado de Fox, 1988, p. 233].

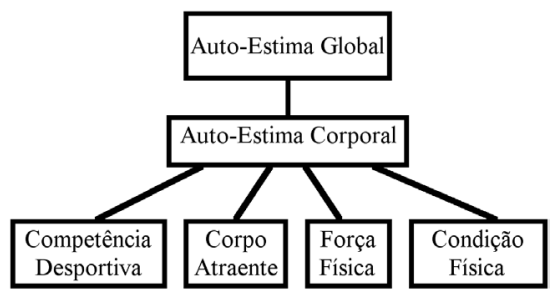

Figura 2. Hipótese dos três níveis de organização hierárquica da auto-estima [adaptado de Fox, 1988, p. 237; Fox \& Corbin, 1989, p. 414]. 
O auto-conceito e a auto-estima evoluem desde a infância até à idade adulta, sofrendo variações em função das interacções e da percepção da competência social (4). Harter (14) sugere que as crianças não se sentem igualmente capazes em todos os domínios de competência e que as crianças com 8 anos ou mais velhas não apenas fazem julgamentos claros acerca da sua competência em diferentes domínios, mas também constroem nestas idades uma imagem do seu valor global como pessoas, num nível superior aos julgamentos de competência específica. À medida que as crianças maturam e se tornam adolescentes, a sua auto-estima torna-se diferenciada, ou seja, os vários domínios tornam-se menos relacionados entre si. Complementarmente, o auto-conceito e a auto-estima vão-se desenvolvendo com base num processo de comparação social. Durante a fase inicial da adolescência ocorrem importantes alterações fisiológicas e psicológicas nos indivíduos, que muito provavelmente se reflectem nas suas auto-percepções. Trata-se de um período em que os adolescentes têm que se ajustar a um corpo em alteração e sujeito a maturação. É um momento em que novas estruturas cognitivas emergem, e é uma altura que tem sido sugerida como um momento de intensificação do papel dos géneros (19).

Existe actualmente um corpo de literatura emergente que examina as diferenças entre géneros relativamente às auto-percepções entre várias populações de diferentes idades. Como Fox (7) sugere, é sensato conduzir análises separadas por género em estudos no âmbito das auto-percepções, de modo a que diferenças imperceptíveis entre géneros não sejam perdidas. Na maioria dos casos, os resultados são consistentes no que diz respeito quer às diferenças, quer às similaridades entre sexos. As diferenças de género consistentes com os estereótipos sexuais parecem ocorrer em facetas específicas do self (20). O padrão principal revela que o sexo feminino reporta consistentemente mais percepções desfavoráveis da sua aparência e da sua competência desportiva, duas das dimensões que definem o self físico (18). No entanto, aparentemente, em crianças fisicamente activas não se registam diferenças entre géneros (18). Fox $(10,11,12)$ analisou de forma sistemática os estudos nos quais o exercício foi utilizado como meio para promover a auto-estima física e outras importantes auto-percepções como a imagem corporal. Segundo Fox, um aumento claro da auto-estima não é um produto automático da aplicação de programas de exercício, no entanto pode ocorrer com certos regimes de exercício e com certas pessoas, dependendo da importância atribuída ao exercício por essas mesmas pessoas. Os efeitos positivos podem ser experimentados tanto pelo sexo masculino como pelo feminino e também por todos os grupos etários, se bem que neste caso as alterações mais vincadas ocorram nas crianças e em adultos de meia-idade. Vários tipos de exercício levam a uma mudança das auto-percepções, mas existe mais evidência da eficácia do exercício aeróbio e treino com pesos, com este último a indicar uma maior eficácia em curto período de tempo. Por outro lado, os programas de exercício devem demorar pelo menos 12 semanas para se registarem alterações significativas, já que, segundo Fox, um extenso período de prática garante mais facilmente melhorias fisiológicas que, quando percebidas pelo sujeito, promovem a melhoria da percepção da sua imagem corporal. Também os factores de adesão não podem ser dissociados daqueles que promovem a auto-estima. Condições que tornam os programas de exercício atraentes, tais como as qualidades do líder ou o ambiente em que se desenrola o exercício, podem ser críticas para mudanças na auto-estima. Fox refere assim que o exercício pode ser utilizado para promover auto-percepções físicas positivas, mas os mecanismos segundo os quais tais mudanças ocorrem não são claros. A influência de programas de actividades de aventura e de ar livre nas auto-percepções tem sido tema de um número considerável de estudos (3), dos quais se destacam os programas Outward Bound*, que parecem produzir mudanças consistentes ao nível de várias dimensões do self. Marsh, Richards e Barnes (24) estudaram as alterações e estabilidade em múltiplas dimensões do auto-conceito a partir dos efeitos da participação num programa de actividades de ar livre muito exigente tanto em termos físicos como psicológicos designado Outward Bound Program, com uma duração de 26 dias. Neste estudo a amostra foi constituída por 27 grupos num total de 361 sujeitos de ambos os sexos, com idades compreendidas entre os 17 e os 29 anos. O instrumento de medida utilizado foi o Self Description Questionnaire 
III (23), tendo os autores do estudo registado aumentos significativos em todos os domínios entre o início e o final do programa, demonstrando que o auto-conceito pode ser modificado através de uma intervenção eficaz. A melhoria não foi tão elevada em quatro domínios identificados à partida como menos relevantes para os objectivos do programa (Académico, Religião, Matemática, e Relações com o Sexo Oposto).

Para Berger e McInman (3), as actividades desenvolvidas nos programas de aventura e ar livre parecem ser um excelente tipo de exercício. Não obstante o resultado deste estudo, conclusões definitivas sobre a relação entre este tipo de exercício e auto-estima são prematuras devido à fraca metodologia que caracterizou muitas investigações no passado. A escola e a família constituem contextos privilegiados de interacção e são determinantes enquanto factores de formação (31) e desenvolvimento da auto-estima. Atendendo a que as crianças e os jovens passam uma parte significativa do seu tempo na escola, esta constitui-se um local privilegiado para a sua socialização, bem como para o seu processo de construção de identidade (30). Assim, crê-se que os cenários mais promissores pelo impacto na saúde pública passam pelas escolas na medida em que, virtualmente, todas as crianças podem ser abrangidas por programas de intervenção e porque as escolas possuem uma infraestrutura vocacionada para a Educação Física. O estudo da relação entre a auto-estima e a prática desportiva em contexto escolar torna-se, deste modo, vital para o planeamento de intervenções e para a acção dos professores de Educação Física. Uma vez que os desportos de aventura já fazem parte dos currículos nacionais de Educação Física, a sua prática tem-se generalizado e começa a fazer parte do quotidiano de inúmeras escolas. Pelas características intrínsecas que este tipo de exercício possui e devido a ser muitas vezes praticado em meio natural, são-lhe atribuídos por professores e educadores, efeitos benéficos no comportamento e bem-estar dos praticantes. Contudo, são escassos os estudos que têm decorrido na área das actividades de aventura e abordado a problemática das auto-percepções, respeitando uma metodologia credível e recorrendo à utilização de instrumentos válidos e fiáveis.
Objectivos do Estudo: o presente estudo teve como propósito averiguar e compreender melhor as relações entre a prática de actividades físicas de aventura e os efeitos psicológicos associados, designadamente ao nível da auto-estima. Para tal, foi objecto de pesquisa o desenvolvimento de um programa de actividades de aventura de âmbito escolar, no sentido de se perceber o modo como este tipo de actividade pode, ou não, contribuir para a melhoria das auto-percepções dos participantes.

Com o presente projecto de trabalho pretendeu-se verificar a influência de um Programa de Desporto Aventura no desenvolvimento da auto-estima global e da auto-estima física, assim como na importância atribuída à auto-estima física dos alunos participantes. Especificamente procurou-se dar resposta a um conjunto de dúvidas de pesquisa: (1) verificar a influência do Programa de Desporto Aventura na modificação da auto-estima global em alunos pré-adolescentes e adolescentes pertencentes a núcleos de Desporto Escolar; (2) verificar a influência do Programa de Desporto Aventura na modificação da auto-estima física, consubstanciada em auto-percepções de competência e adequação (competência desportiva, condição e força física e corpo atraente); e (3) verificar a influência do Programa de Desporto Aventura na modificação da importância atribuída às dimensões da auto-estima física, acima referenciadas.

\section{MATERIAL E MÉTODOS Amostra}

A amostra do Grupo Experimental (GE) foi constituída por alunos dos $6^{\circ}, 7^{\circ}, 8^{\circ}, 9^{\circ}$ e $10^{\circ}$ anos de escolaridade pertencentes a três núcleos escolares de desporto aventura de Escolas Básicas do concelho de Albufeira e do concelho de Loulé. O Grupo Controlo (GC) foi constituído pelos núcleos escolares de desporto aventura existentes no barlavento algarvio, pertencentes a quatro escolas. No GE a amostra foi composta por 38 sujeitos, com idades compreendidas entre os 12 e os 18 anos de idade $(M=14,50$ e $\mathrm{DP}=1,33)$, dos quais 15 raparigas $(\mathrm{M}=14,53 \mathrm{e}$ $\mathrm{DP}=1,06)$ e 23 rapazes $(\mathrm{M}=14,48$ e $\mathrm{DP}=1,50)$, enquanto que o GC foi constituído por 28 sujeitos, igualmente com idades entre os 12 e os 18 anos de idade $(M=14,89$ e $D P=1,55)$, em que 9 eram raparigas $(M=14,78$ e $\mathrm{DP}=1,30)$ e 19 eram rapazes $(\mathrm{M}=14,95$ e $\mathrm{DP}=1,68)$. 


\section{Procedimentos}

Após autorização do Centro de Área Educativa do Algarve foram contactados os professores responsáveis pelos núcleos de desporto aventura que viriam a fazer parte do GE, bem como os professores responsáveis pelos núcleos que viriam a fazer parte do GC. Aos professores do GC foi solicitado que disponibilizassem dois momentos, em duas actividades, para aplicação dos questionários. Aos professores do GE foi solicitado que implementassem e dinamizassem em conjunto o programa de actividades de desporto aventura proposto. Em reuniões periódicas com estes professores foram estruturadas as sessões do programa de intervenção (aspectos logísticos, organização das sessões) e foram sistematizados os estilos de liderança preconizados no programa experimental. Foi fornecida informação sobre o programa e seus principais objectivos e solicitada autorização a todos encarregados de educação.

\section{Desenho experimental}

O programa experimental de intervenção (Programa de Desporto Aventura) decorreu durante o segundo período escolar, tendo a organização curricular condicionado o desenho e o tempo de duração do programa. Por este motivo, o tempo de duração do programa foi menor do que o proposto por autores como Fox $(10,11)$. Assim, o programa teve início no dia 12 de Janeiro de 2002, coincidente com a realização da avaliação inicial dos sujeitos, prolongou-se por 10 semanas e terminou no dia 25 de Março de 2002 quando se procedeu à avaliação final dos sujeitos e à avaliação do programa por parte dos participantes. No total realizaram-se 12 sessões.

\section{Instrumentos}

Foram utilizados os instrumentos Perfil de Auto-Percepção Física para Crianças e Jovens - PAPF-CJ, Perfil de Importância Percebida para Crianças e Jovens - PIP-CJ

(2) traduzidos a partir do Physical Self-Perception Profile for Children and Youth e Perceived Importance Profile for Children and Youth (33). No pós-teste, simultaneamente, foram aplicados aos sujeitos questionários de auto-avaliação e de apreciação das sessões e do programa, elaborados para o efeito, com o objectivo de se obterem informações de natureza qualitativa que complementassem os dados da investigação.
O Physical Self-Perception Profile for Children and Youth PSPP-CY (33), é uma versão para crianças e adolescentes adaptada a partir do Physical Self-Perception Profile - PSPP (13), mas que contempla também dimensões do instrumento Self-Perception Profile for Children (15). O PSPP-CY pretende analisar o modo como as crianças e jovens percepcionam a sua competência em diferentes domínios do self físico e como avaliam a sua auto-estima. O PSPP-CY tem seis sub-escalas que representam uma organização de factores de auto-estima. Esta organização contempla uma sub-escala geral de auto-estima global, engloba uma sub-escala de auto-estima física global e contém quatro sub-escalas de factores de competência. São as seguintes as sub-escalas do PSPP-CY : (i) Condição Física / Condição - esta sub-escala procura avaliar as percepções do nível de condição física, resistência ou forma física; (ii) Competência Desportiva / Desporto - esta sub-escala destina-se a avaliar as percepções de habilidade física e desportiva, ou seja, o modo como a criança ou o adolescente percepcionam a sua competência para realizar actividades físicas e desportivas; (iii) Corpo Atraente / Corpo - esta sub-escala pretende avaliar o grau de satisfação e a confiança na própria aparência, assim como a capacidade da criança ou do adolescente manterem um corpo atraente; (iv) Força Física / Força - esta sub-escala tenciona avaliar as percepções de força, desenvolvimento muscular e a confiança em situações que exigem força física; (v) Auto-Estima Física / AEF - esta sub-escala procura avaliar sentimentos gerais de felicidade, satisfação, orgulho, respeito, e confiança no próprio corpo; e (vi) Auto-Estima Global / AEG - esta sub-escala pretende avaliar até que ponto o indivíduo gosta de si próprio enquanto pessoa; constitui portanto, um juízo global do valor da criança ou do adolescente enquanto pessoas e não um domínio específico de competência. Todas as sub-escalas têm seis itens cuja pontuação é obtida usando um formato alternativo estruturado em quatro pontos. Existe evidência que revela que este formato reduz a tendência para se fornecer respostas socialmente desejáveis e, deste modo, promove uma redução do risco de enviesamento de resultados (e.g. $14 ; 15 ; 16 ; 6)$, já que, face ao tipo de formulação das questões e ao processo de escolha que exige, é transmitida ao sujeito a sensa- 
ção que todo o leque de respostas é aceitável. A chave de cotação da escala é obtida através da média das seis sub-escalas que, no seu conjunto, definem o "perfil" de cada criança ou adolescente.

O Perceived Importance Profile for Children and Youth PIP-CY (33) é baseado no Perceived Importance Profile de Fox (7). Este foi construído para complementar o PSPP e providenciar uma medida da importância atribuída pelos indivíduos a factores relativos ao self físico, concretamente aos seus níveis respectivos de competência desportiva, força física, condição física e corpo atraente, por forma a aceder à sua auto-estima física. Assim, o instrumento é conceptualizado como um ecrã ou filtro estabelecido entre as pontuações das auto-percepções em cada um dos sub-domínios e a auto-estima física dos indivíduos. O PIP-CY é constituído por quatro sub-escalas de dois itens cada, e foi desenhado de acordo com os conteúdos dos sub-domínios do PSPP-CY (Condição, Desporto, Corpo e Força).

\section{Condições de aplicação dos instrumentos}

No início do programa experimental foi explicado sucintamente o objectivo do estudo, foi fornecida informação acerca do que cada questionário pretendia avaliar e foram dadas a conhecer as actividades a desenvolver (objectivos, datas e locais). No pré-teste e no pós-teste as instruções de preenchimento dos instrumentos foram apresentadas pelo investigador. A confidencialidade dos dados individuais recolhidos foi assegurada, tendo para tal cada sujeito criado um código pessoal, com o qual identificou os questionários por si preenchidos.

\section{Intervenção}

O programa consistiu em actividades habitualmente levadas a cabo pelos núcleos escolares de desporto aventura, designadamente, Escalada, Montanhismo, Manobras com Cordas, Orientação, Canoagem, BTT (bicicletas todo-o-terreno), Campismo, ou Tiro com Arco, numa dinâmica de intercâmbio em todas as sessões entre os três núcleos participantes. Em cada sessão foram definidos objectivos operacionais ao nível das actividades seleccionadas. As práticas realizaram-se em meio natural e nas próprias escolas. $\mathrm{O}$ enquadramento das actividades foi efectuado em conjunto pelos professores dos respectivos núcleos participantes, que formaram a equipa de intervenção. Houve sempre a preocupação de os professores se alternarem na apresentação das actividades e rodarem no enquadramento dos grupos, de forma a contrabalançar os seus efeitos individuais nos participantes. As sessões foram planeadas atendendo à segurança de todos os sujeitos envolvidos, pelo que foi implementado um conjunto de regras de segurança gerais para todas as sessões e específicas em função dos conteúdos de cada sessão. As sessões foram igualmente desenhadas atendendo aos níveis de competências dos participantes, na tentativa de proporcionar a todos os indivíduos, em cada actividade, um nível semelhante de desafio e de risco. Como tal, em função das competências evidenciadas pelos sujeitos nas diferentes actividades, foram criados níveis de dificuldade. Cada participante podia integrar diferentes níveis de dificuldade, em função do seu desempenho nas diferentes modalidades. Desta forma, foi possível incluir plenamente nas actividades tanto os alunos com pouca competência, como os alunos com elevada competência. Ao estabelecer-se um leque alargado de situações de prática, procurou-se, tal como sugerido por Matos (25) e Matos, Simões e Carvalhosa (26), que as actividades fossem capazes de envolver os participantes no programa, de modo a evitar desistências e manter o interesse dos jovens. Estabeleceu-se um critério de $75 \%$ de presenças como mínimo, para os jovens serem incluídos no protocolo de avaliação.

\section{APRESENTAÇÃO DOS RESULTADOS}

No GE, com excepção da dimensão Força do PAPFCJ para o sexo feminino, tanto no pré-teste como no pós-teste, todos os valores médios se encontram acima de 2,5, revelando na globalidade pontuações de importância, percepção física e auto-estima elevadas. Através da análise dos resultados dos testes Kolmogorov-Smirnov (K-S) e Shapiro-Wilk (S-W) foi possível verificar para todas as variáveis quais as distribuições que respeitam o requisito da normalidade. Nos casos em que este requisito se cumpriu foi possível aplicar testes paramétricos, enquanto que nos casos em que a normalidade não foi observada recorreu-se à estatística não paramétrica. 


\section{Comparação entre géneros}

Para analisar as diferenças entre sexos utilizou-se o teste $t$ para amostras independentes, quando a normalidade foi respeitada. Nos casos de não normalidade recorreu-se ao teste não paramétrico de MannWhitney. O Quadro I resume as diferenças existentes entre géneros, nos sujeitos do GE, quer no pré-teste quer no pós-teste. Na linha dos resultados obtidos aquando do estudo das propriedades psicométricas do PAPF-CJ (2), os rapazes do GE apresentaram pontuações superiores em todas as dimensões em relação às raparigas, tanto no pré-teste como no pós- -teste. Porém, apenas se observaram diferenças estatisticamente significativas entre os dois sexos no pós-teste nas dimensões Condição $(U=-3,179 ; p<$ $.01)$ e Força $(U=-2,674 ; p<.01)$. Relativamente à importância atribuída pelos sujeitos às dimensões da auto-estima física, verificou-se que não existiram diferenças significativas entre géneros em ambos os momentos de avaliação. Não obstante, apesar de não significativas, verificaram-se algumas mudanças após o período de intervenção na importância relativa que cada género atribuiu às diferentes dimensões da auto-estima física.

Quadro I - Diferenças em função do Género no Pré-teste e no Pós-teste nas Dimensões do PAPF-CJ e PIP-CJ no Grupo Experimental - GE (n=38).

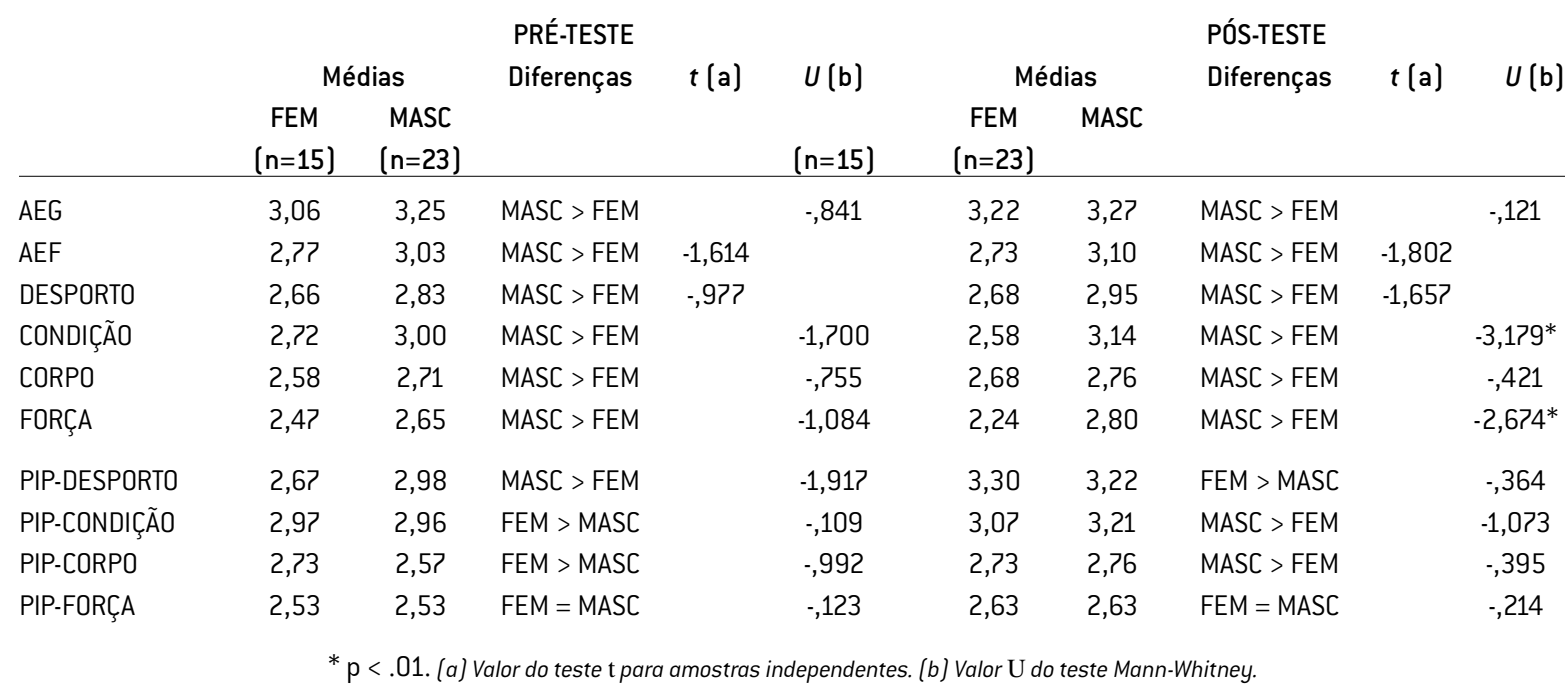

\section{Evolução das variáveis}

O Quadro II considera as diferenças no PAPF-CJ e no PIP-CJ entre os dois momentos de avaliação, no GE e no GC. Quando a normalidade foi verificada utilizouse o teste $t$ de pares. Nos casos de não normalidade recorreu-se ao teste não paramétrico de Wilcoxon. No GE, considerando toda a amostra, observou-se uma evolução positiva entre o pré-teste e o pós-teste (com excepção da dimensão Força que se manteve estável), se bem que as diferenças não sejam significativas. As raparigas não diferiram significativamente entre os dois momentos de avaliação, no entanto, observaram-se alterações nas dimensões AEF, Condição e Força, que registaram uma diminuição entre o pré-teste e o pós-teste, enquanto que nas dimensões de AEG, Desporto e Corpo se observou uma subida dos seus valores médios. Por sua vez, os rapazes apresentaram uma subida em todas as dimensões do PAPF-CJ do pré-teste para o pós-teste, tendo essa subida sido significativa na dimensão Condição $(W=-2,075 ; \mathrm{p}<.05)$. No caso do GC, registou-se uma diminuição dos valores médios em 
todas as dimensões no sexo feminino e quando se considera a totalidade da amostra, se bem que essas diferenças não tenham sido estatisticamente significativas. Para o sexo masculino, apesar de também não se observarem diferenças significativas entre $o$ pré-teste e o pós-teste, foi possível verificar uma ténue subida nos valores médios das dimensões de Desporto, Condição e Corpo, e uma ligeira descida das restantes dimensões.
O GE apresentou ainda uma subida consistente entre os dois momentos de avaliação em todas as dimensões de importância da auto-estima física, à excepção da dimensão PIP-Força entre as raparigas, que se manteve estável. Todavia, só se observaram diferenças significativas entre os dois momentos de avaliação na dimensão PIP-Desporto na amostra total $(W=-3,063 ; \mathrm{p}<.01)$ e nas raparigas $(W=-2,969$; $\mathrm{p}<.01)$.

Quadro II - Diferenças entre o Pré-teste e o Pós-teste nas Dimensões do PAPF-CJ e do PIP-CJ no Grupo Experimental (GE) e no Grupo Controlo (GC).

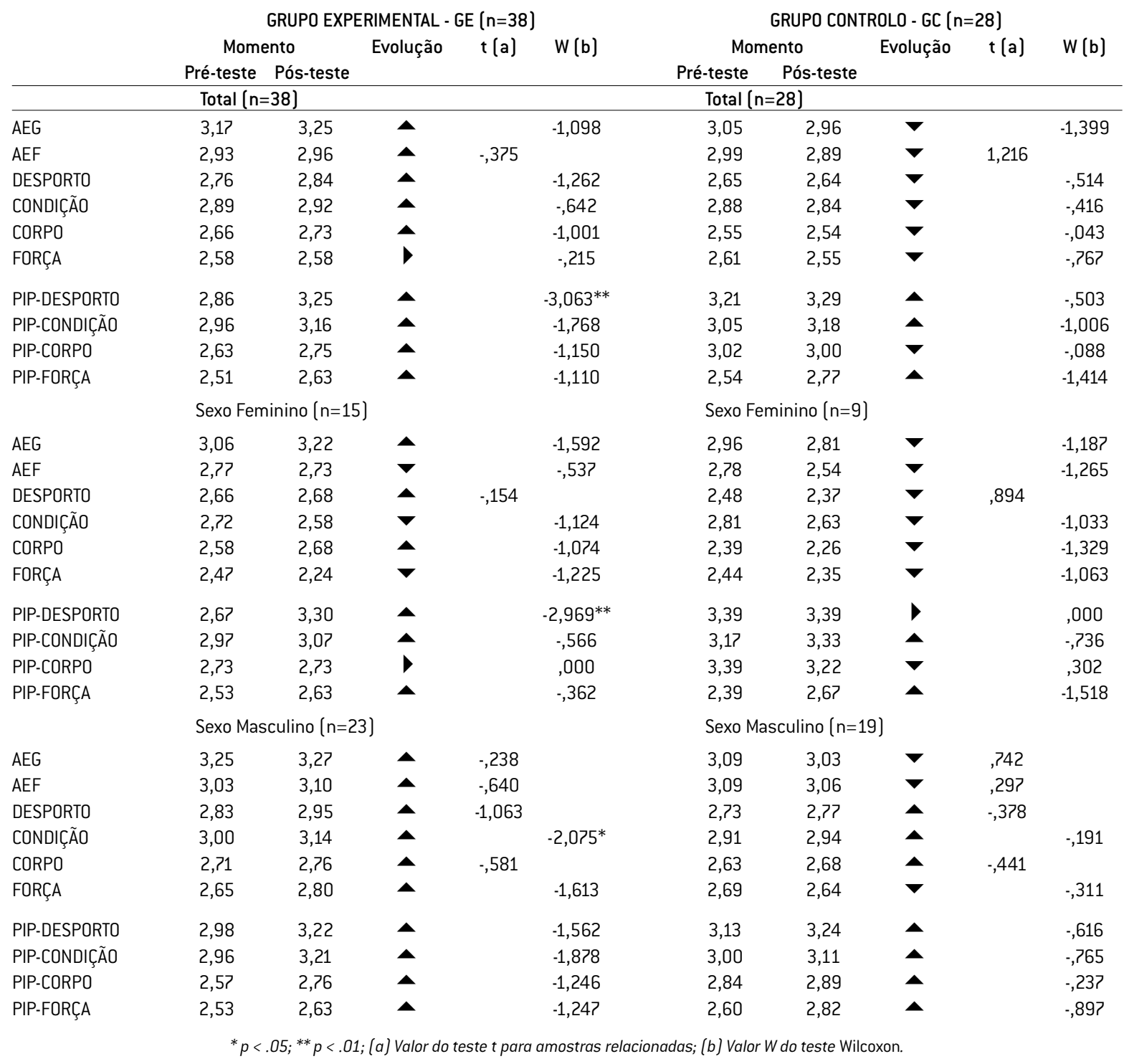




\section{Comparação entre grupos}

No sentido de verificar as diferenças existentes entre o GE e o GC recorreu-se ao teste $t$ para amostras independentes quando a normalidade foi verificada. Nos casos de não normalidade, recorreu-se ao teste não paramétrico de Mann-Whitney. O Quadro III resume as diferenças ao nível do PAPF-CJ e do PIPCJ entre o GE e GC em ambos os momentos de avaliação, considerando a totalidade da amostra e em função do género.

Quadro III - Diferenças entre o Grupo Experimental (GE) e o Grupo Controlo (GC), no Pré-teste e no Pós-teste nas Dimensões do PAPF-CJ e do PIP-CJ.

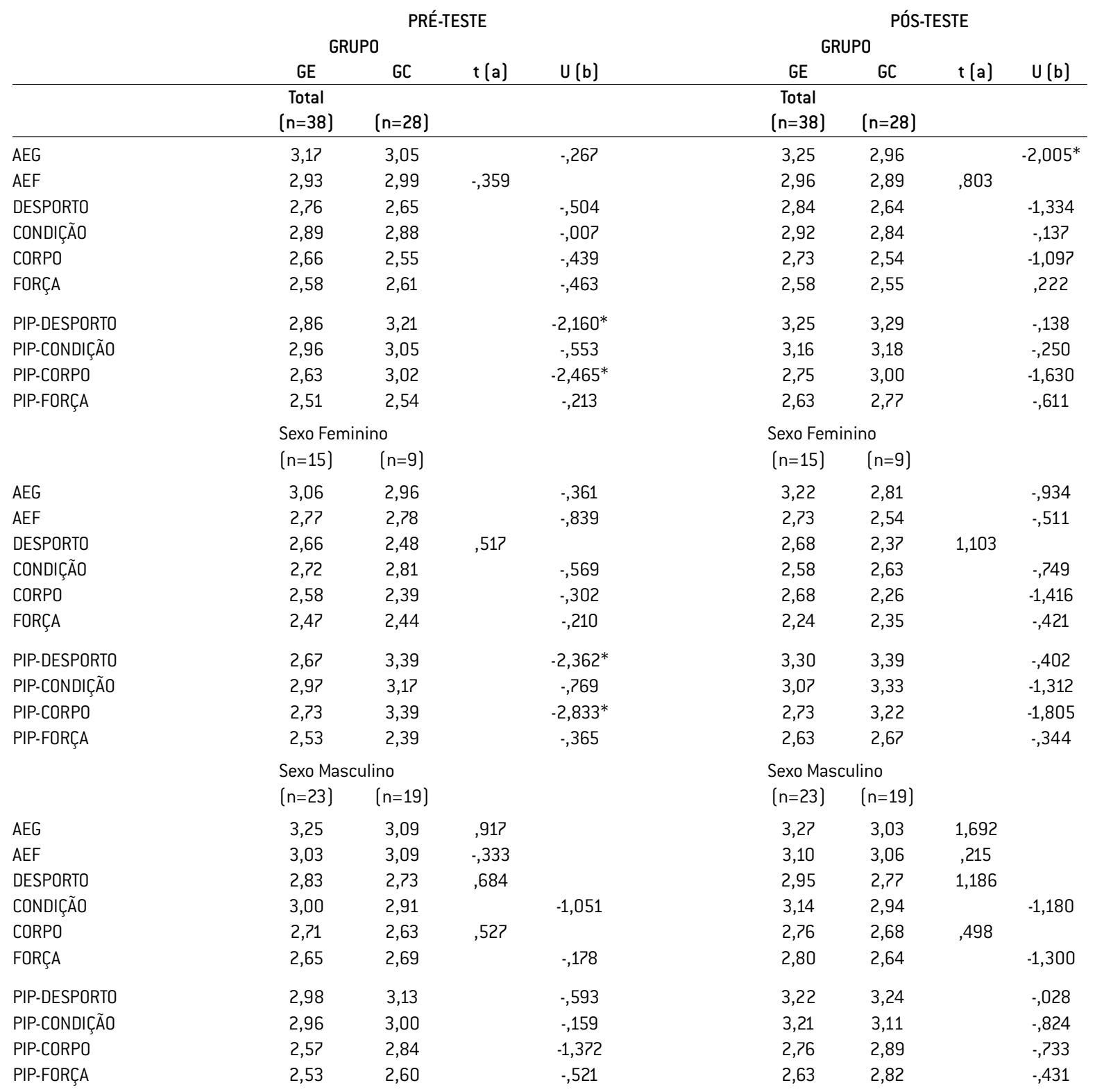

${ }^{*} p<.05$; (a) Valor do teste t para amostras independentes; (b) Valor $\mathrm{U}$ do teste Mann-Whitney. 
Em relação ao PAPF-CJ, as únicas diferenças estatisticamente significativas situam-se ao nível da AEG no pós-teste quando se considera a amostra total ( $U$ $=-2,005 ; \mathrm{p}<.05)$. Observando as médias, constatase a existência de um padrão de evolução nos resultados dos participantes do GE, quando se considera a amostra na sua totalidade e entre o sexo masculino. Os sujeitos deste grupo passaram a apresentar valores superiores no pós-teste em todas as dimensões do PAPF-CJ, comparativamente com os sujeitos do GC. Este padrão não é tão claro entre o sexo feminino, apresentando as raparigas do GC valores superiores nas dimensões Condição e Força no pós-teste. Relativamente ao PIP-CJ verifica-se que existem diferenças estatisticamente significativas entre ambos os grupos no pré-teste, nas dimensões de importância PIP-Desporto e PIP-Corpo, quando se considera a amostra na sua totalidade $(U=-2,160$; $p<.05$ e $U=-2,465 ; p<.05$, respectivamente) e quando se considera o sexo feminino $(U=-2,362$; $p<.05$ e $U=-2,833 ; p<.05$, respectivamente). Todavia, estas diferenças diluíram-se no pós-teste.

\section{Análise qualitativa efectuada no pós-teste}

No sentido de apurar dados complementares que contribuíssem para a justificação dos resultados obtidos com os sujeitos do GE, na avaliação final foram passados questionários de satisfação, dos quais a seguir se apresentam os resultados mais relevantes. Inquiridos sobre se o programa tinha correspondido às suas expectativas, os sujeitos responderam em escala analógico-visual (entre zero e dez), tendo as raparigas apresentado um valor médio de 9,48 (DP $=0,59)$ e os rapazes um valor médio de $8,62(\mathrm{DP}=$ $1,21)$. Segundo o teste $U$ de Mann-Whitney, apuraram-se diferenças significativas entre os sexos $(U=$ -2,290; $p$ < .05). Na questão "Em termos gerais, o que achaste do Programa?" os aspectos referidos mais vezes pelos sujeitos foram os seguintes: "bom" $(39,5 \%)$, "interessante" $(28,9 \%)$, "divertido" $(28,9 \%)$ e "desafiante" (10,5\%). Uma vez que se tratava de uma pergunta aberta, cada sujeito podia avançar com mais de uma opinião, o que veio a acontecer. De referir que neste ponto os sujeitos só referiram aspectos positivos. À questão "Gostaste de praticar as actividades do programa?", os sujeitos responderam em escala analógico-visual, tendo as rapa- rigas apresentado um valor médio de 9,53 (DP $=$ 0,51 ), enquanto que os rapazes apresentaram um valor médio de 9,49 $(\mathrm{DP}=0,66)$. Na questão "Refere o que mais te agradou", dos motivos mais referidos pelos participantes destacaram-se claramente como aspecto positivo do programa as actividades realizadas $(73,7 \%)$, seguindo-se os locais onde as actividades se realizaram $(18,4 \%)$ e a possibilidade de o programa ter permitido aos sujeitos fazerem novos amigos $(18,4 \%)$. Os dados relativos à questão "Estarias disposto a voltar a participar num programa de actividades semelhante? Porquê?", revelaram a unanimidade dos sujeitos mostrando-se disponíveis para voltarem a participar num programa de actividades idêntico ao que tinham acabado de finalizar. Poucos participantes avançaram contudo motivos para justificar essa afirmação, sendo os aspectos mais representativos os seguintes: "porque se praticam novas actividades" $(10,5 \%)$, "porque me faz bem" $(10,5 \%)$ e "porque gosto destas actividades" (7,9\%)

\section{DISCUSSÃO}

A partir da análise dos resultados da Auto-Estima Global verifica-se um aumento nesta dimensão nos sujeitos do GE, ao contrário do que sucede no GC. Enquanto que raparigas e rapazes do GC relataram diminuições na sua auto-estima, no GE, em ambos os sexos, observou-se um aumento da auto-estima. Todavia, os aumentos verificados na auto-estima nos participantes do GE não foram significativos. Apesar de os rapazes apresentarem valores de auto-estima superiores aos das raparigas nos momentos de avaliação inicial e final, tanto no GE como no GC, em nenhum dos casos considerados as diferenças foram significativas. A auto-estima é um constructo bastante estável e de difícil mudança; é pois interessante constatar esta evolução diferenciada entre os dois grupos, mesmo não sendo significativas as diferenças. O maior aumento registado (ainda que não significativo) ocorreu nas raparigas do GE, aproximando-se claramente do valor de auto-estima relatado pelos rapazes do mesmo grupo. Estes dados são semelhantes aos relatados no estudo de Ebbeck e Gibbons (5), sugerindo que um tipo de exercício com um carácter mais cooperativo tem um efeito potencialmente superior para as raparigas, quer crianças quer adolescentes, ao nível da auto-estima 
global. O facto de as modificações no GE não serem significativas pode ficar a dever-se ainda ao facto de estes sujeitos apresentarem à partida valores bastante elevados de auto-estima. Tal pode depreender-se efectuando a comparação entre os valores dos sujeitos do GE com os resultados obtidos na amostra utilizada para a validação do PAPF-CJ, que, à partida, pode ser considerada proveniente de uma "população normal" (2). Também o tempo de duração do programa (10 semanas) parece ter sido insuficiente para produzir efeitos mais positivos. Este facto está de acordo com as sugestões de Fox $(10,11,12)$, segundo o qual se prevê que o envolvimento em programas de exercício demore pelo menos 12 semanas para que se possam verificar alterações significativas ao nível da auto-estima global dos participantes. Por outro lado, regista-se que no final do período experimental passaram a verificar-se diferenças significativas entre o GE e GC, que não existiam na avaliação inicial. Este conjunto de resultados parece indiciar que o Programa de Desporto Aventura teve o efeito de consolidar e aumentar ligeiramente os valores iniciais elevados de auto-estima dos participantes do $\mathrm{GE}$, pelo que, de alguma forma, poderá ter contido uma tendência para a diminuição da auto-estima, como a que se registou entre os sujeitos do GC. Esta tendência de descida é apontada por Matos, Simões, Carvalhosa, Reis e Canha (27) no seu estudo nacional sobre a saúde dos adolescentes portugueses, em que verificaram que os adolescentes mais velhos eram aqueles que apresentavam mais frequentemente sintomas de mal-estar físico e psicológico, menos auto-confiança e fraca imagem pessoal, comparativamente com os mais novos que mais frequentemente afirmavam sentir-se confiantes e felizes. Os resultados registados no presente estudo estão ainda de acordo com a assunção segundo a qual os constructos relativos ao self são extremamente resistentes à mudança (17). Desta forma, os resultados obtidos fornecem suporte para a ideia defendida por alguns investigadores, para quem a participação em actividades físicas e desportivas tem um efeito positivo, mas reduzido, na auto-estima global (22).

Embora não tenham sido assinaladas diferenças significativas ao nível da AEF, verifica-se uma evolução global positiva dos sujeitos do GE no final da aplicação do programa, enquanto que, ao invés, no GC se assiste a uma diminuição generalizada da auto-estima física. Em termos gerais o programa parece ter tido um efeito positivo na auto-estima física dos sujeitos participantes, contudo, possivelmente não terá tido a duração suficiente para se consolidar uma mudança significativa na percepção física dos indivíduos. Nesse sentido, conforme referem Berger e McInman (3), a duração dos programas de aventura é essencial para o registo de resultados consistentes ao nível das auto-percepções físicas, já que o tempo de prática proporciona aos indivíduos uma percepção de competência promovida pelas actividades realizadas, bem como um conhecimento mais aprofundado das suas capacidades e dos seus limites.

Tanto no GE como no GC, os rapazes apresentaram percepções de competência e uma auto-estima física superiores às das raparigas, quer na avaliação inicial quer na avaliação final. No final do Programa de Desporto de Aventura, observaram-se diferenças significativas no GE entre géneros, com os rapazes a apresentarem competências mais elevadas de Condição e Força. Estas diferenças resultam da diminuição de competência relatada pelas raparigas e aumento de competência assinalado por parte dos rapazes. Nesta perspectiva, o programa de intervenção parece ter tido um impacto maior na auto-estima física dos rapazes do GE, tendo-se registado uma evolução positiva nas suas percepções físicas, se bem que só se tenham registado diferenças significativas entre a avaliação inicial e final na variável Condição. Entre as raparigas do GE, ainda que as diferenças não tenham sido significativas, a diminuição da auto-estima física deve-se sobretudo à diminuição da percepção de competência de Condição e Força. Por outro lado, verifica-se que no final do programa as raparigas do GC apresentam decréscimos, ainda que não significativos, na sua auto-estima física e em todas as suas percepções de competência. Deste modo, a diminuição da percepção de competência de Condição e Força das raparigas do GE no final do programa pode ficar a dever-se às características do programa e às actividades desenvolvidas, ou mais provavelmente ao facto de o programa não ter conseguido inverter totalmente uma eventual tendência de diminuição das percepções de competência entre as raparigas adolescentes. Os rapazes apresentam, no final do Programa de Desporto Aventura, uma tendência de 
mudança do seu perfil de auto-percepção física. Este padrão sistemático de melhorias, ainda que não significativas, foi obtido num intervalo de tempo relativamente curto, tal como foi referido anteriormente. Os sujeitos do GC atribuem maior importância aos domínios da auto-estima física do que os sujeitos do GE, existindo diferenças significativas no pré-teste na importância atribuída à competência desportiva (variável PIP-Desporto) e ao corpo atraente (variável PIP-Corpo). Todavia, estas diferenças diluem-se no final do período experimental, já que o GE apresenta uma subida generalizada da importância atribuída aos domínios da auto-estima física, ainda que só se registem diferenças significativas entre o pré e o pós-teste na importância atribuída ao desporto (variável PIP-Desporto) nos sujeitos do GE. Neste ponto, o programa parece ter contribuído para um aumento da importância atribuída pelos sujeitos à competência e adequação no âmbito da auto-estima física. A partir da análise dos resultados por género, verifica-se uma subida consistente na importância atribuída pelos sujeitos de ambos os sexos do GE aos domínios da auto-estima física, embora só se registem diferenças significativas no final do programa experimental na variável PIP-Desporto entre as raparigas. Existem diferenças significativas nas variáveis PIP-Desporto e PIP-Corpo no início do período experimental entre as raparigas de ambos os grupos, com as raparigas do GC a atribuir maior importância ao Desporto e ao Corpo. No entanto, no final do período experimental essas diferenças foram anuladas. No primeiro caso, devido a uma subida significativa da importância atribuída ao Desporto por parte das raparigas do GE e, no segundo caso, devido a uma redução da importância atribuída ao Corpo pelas raparigas do GC. Na primeira situação, o envolvimento das raparigas do GE no programa parece ter contribuído para um aumento da importância com que estas passaram a encarar os aspectos relativos à competência no âmbito da auto-estima física. Na segunda situação considerada, as raparigas do GC parecem ter tido dificuldades em manter a elevada importância atribuída à competência desportiva e física. Entre os rapazes dos dois grupos verifica-se um padrão semelhante de aumento da importância atribuída a todos os domínios da auto-estima física, embora não se assinalem diferenças significa- tivas no final do período experimental, quer entre ambos os grupos, quer entre a avaliação inicial e final nos dois casos considerados. No GE, tanto na avaliação inicial como na final, observa-se que ambos os sexos atribuem igual importância à competência de força, enquanto que nas restantes variáveis não se registam diferenças significativas. No final do programa as raparigas passaram a atribuir maior importância ao Desporto do que os rapazes, fruto da evolução significativa das raparigas neste domínio, apesar da diferença não ser significativa. Sob este aspecto, o programa parece ter contribuído para alterar o estereótipo sexual segundo o qual os rapazes valorizam mais o Desporto do que as raparigas. As restantes mudanças operadas pelo Programa de Desporto Aventura, embora maioritariamente no sentido positivo, não foram significativas, provavelmente porque o programa não teve a duração necessária para alterar de forma estatisticamente significativa a importância atribuída por todos os sujeitos à condição física e à força, assim como ao seu corpo. Neste curto período de tempo, os sujeitos parecem ter valorizado mais o aspecto desportivo, aquele que aparentemente estava relacionado mais directamente com o programa de intervenção.

De salientar que aumentos do desempenho podem, paradoxalmente, sob certas condições, provocar diminuições da auto-estima. Se como consequência da melhoria de competências um participante tem acesso a um novo quadro de referência mais complexo e de dificuldade crescente, então a sua auto-estima e auto-eficácia podem diminuir. Por exemplo, quando um jovem jogador de um clube se junta a uma selecção, apesar de o seu desempenho poder melhorar, ao relacionar a sua competência com a dos seus novos pares, a sua auto-estima pode decrescer. No caso concreto do presente programa, algo semelhante poderá ter acontecido, na medida em que os jovens provinham de três escolas diferentes e não se conheciam entre si. À partida, os participantes poderiam ter determinadas auto-percepções de competência e um nível de auto-estima influenciados pela ideia de serem os únicos alunos na sua escola que praticavam actividades físicas conotadas com um certo grau de aventura e risco e de confronto com a natureza. Apesar da aquisição e melhoria efectiva de competências, o facto de praticarem actividades com 
novos colegas, alguns deles com níveis de desempenho elevados, pode ter contribuído para que muitos dos participantes provavelmente passassem a ter uma auto-estima global e física mais realistas, traduzindo-se este facto no seu decréscimo. Desta forma, embora o programa não tenha tido um carácter competitivo, os jovens acabam sempre por estabelecer comparações entre si mesmos e os seus pares, o que pode ter induzido uma diminuição das suas auto-percepções. Todavia, a médio e longo prazo julga-se que este tipo de situação possa ser ultrapassada, principalmente caso haja um processo de reflexão e de consciencialização das aquisições conseguidas e um enfoque na orientação para a tarefa. Por outro lado, as experiências de sucesso, desafio e risco proporcionadas pelo programa por si só não foram suficientes para melhorar a auto-estima global e física dos jovens participantes, uma vez que provavelmente seria necessário mais tempo de prática para que os sujeitos se atribuíssem os sucessos obtidos e se sentissem valorizados por eles, bem como um conhecimento mais aprofundado das suas capacidades e dos seus limites (3).

A importância atribuída pelos participantes aos componentes relevantes da auto-estima física, assim como ao programa em geral, parece ter tido um efeito positivo no seu comportamento (elevada adesão, motivação e empenho nas actividades, ou inexistência de problemas de disciplina), mas é provável que os participantes passassem a ser mais críticos consigo próprios nas áreas que sentiam importantes, podendo este facto ter assumido um efeito limitador nas suas auto-percepções.

\section{Limitações e implicações}

Relativamente a aspectos limitativos do presente estudo, constata-se que os instrumentos utilizados e actualmente disponíveis para analisar os constructos da auto-estima global e física se mantêm relativamente simplificados e descritivos, na medida em que se baseiam em auto-relatos. Apesar de os principais instrumentos utilizados em princípio reduzirem a tendência para respostas socialmente desejáveis, como refere Fox (9), é limitativo pretender ter acesso à privacidade dos indivíduos através de instrumentos de papel e lápis, já que na avaliação da auto-estima e do auto-conceito os investigadores estão provavelmente a tentar aceder às mais críticas, controversas e complexas características humanas. Deste modo, tal como se verifica no presente estudo, em futuras pesquisas sugere-se que a aplicação de diferenciadas técnicas qualitativas seja considerada em paralelo com a abordagem quantitativa, única forma de obter um quadro revelador das mudanças operadas.

Por último, é de referir que a partir dos resultados obtidos e dos relatos de satisfação dos participantes é possível afirmar que programas semelhantes de desporto aventura podem ser uma forma inovadora, interessante e motivante de desenvolvimento das auto-percepções e de promoção da actividade física entre os adolescentes, pelo que futuras intervenções devem incorporar este conhecimento.

\begin{abstract}
* A primeira escola a ministrar um programa Outward Bound foi fundada por Kurt Hahn na Escócia em 1941. Os principais objectivos visavam o treino de jovens marinheiros Britânicos, de modo a que resistissem aos perigos da guerra, através do desenvolvimento do seu potencial e uma forte vontade de sobreviver. Actualmente os programas Outward Bound destinam-se sobretudo a jovens adultos, que em pequenos grupos desenvolvem actividades de melhoria da aptidão física, incluindo longas caminhadas, corrida de cross-country, escalada em rocha, canoagem em águas bravas, e outras actividades vigorosas. $\mathrm{O}$ estabelecimento e a realização de objectivos individuais e de grupo em actividades de aventura, assim como a oportunidade de experienciar e lidar com situações stressantes são igualmente componentes importantes dos programas Outward Bound (24).
\end{abstract}

\section{CORRESPONDÊNCIA}

\section{Rui Paulo Bernardo}

Faculdade de Motricidade Humana

Estrada da Costa

1495-688 Cruz Quebrada

Portugal

ruibernardo@aeiou.pt 


\section{REFERÊNCIAS}

1 Baumeister, R. F. (1994). Self-esteem. In V. S. Ramachandran (Ed.) Encyclopedia of Human Behavior. (Vol. 4). San Diego: Academic Press, 83- 87.

2 Bernardo, R.; Matos, M. (2003). Adaptação Portuguesa do Physical Self-Perception Profile for Children and Youth e Perceived Importance Profile for Children and Youth. Lisboa: Faculdade de Motricidade Humana. (Trabalho não publicado).

3 Berger, B.G.; McInman, A. (1993). Exercise and the quality of life. In R. Singer, M. Murphey \& L. Tennant (Eds.), Handbook of research on sport psychology. New York: MacMillan, 729-760.

4 Byrne, B. M.; Shavelson, R. J. (1996). On the structure of social self-concept for pre-, early, and late adolescents: A test of the Shavelson, Hubner, and Stanton (1976) model. Journal of Personality and Social Psychology, 70: 599-613.

5 Ebbeck, V.; Gibbons, S. L. (1998). The effect of a team building program on the self-conceptions of grade 6 and 7 physical education students. Journal of Sport \& Exercise Psychology, 20:300-310.

6 Fox , K. H. (1988). The self-esteem complex and youth fitness. Quest, 40:230-246.

7 Fox, K. R. (1990). The Physical Self-Perception Profile Manual. Illinois: Northern Illinois University.

8 Fox , K. H. (1997). The physical self and processes in selfesteem development. In K. R. Fox (Ed.) The physical self: From motivation to well-being. Champaign, Illinois: Human Kinetics, 111-140.

9 Fox , K. H. (1998). Advances in the measurement of the physical self. In J. L. Duda (Ed.) Advances in sport and exercise psychology measurement. Morgantown: FIT, 295-310.

10 Fox , K. H. (1999). Self-esteem and quality of live in exercise and sport. In Václav Hosek, Pavel Tilinger \& Lubos Bílek (Eds.) Psychology of sport exercise: Enhancing the quality of life. Proceedings of the $10^{\text {th }}$ European Congress of Sport Psychology - Part 1. Prague: FEPSAC, 12-19.

11 Fox, K. H. (2000a). Self-esteem, self-perceptions and exercise. International Journal of Sport Psychology 31:228-240.

12 Fox, K.H. (2000b). The effects of exercise on self-perceptions and self-esteem. In Stuart J. H. Biddle, Kenneth R. Fox \& Stephen H Boutcher (Eds.) Physical activity and psychological well-being . London: Biddles Ltd, Guildford and King's Lynn, 88-117.

13 Fox , K. H.; Corbin, C. B. (1989). The physical self perception profile: Development and preliminary validation. Journal of Sport and Exercise Psychology 11:408-430.

14 Harter, S. (1982). The perceived competence scale for children. Child Development 53: 87-97.

15 Harter, S. (1985). Manual for the self-perception profile for children. Denver: University of Denver.

16 Harter, S. (1988). Manual for the self-perception profile for adolescents. Denver: University of Denver.

17 Harter, S. (1993). Causes and consequences of low selfesteem in children and adolescents. In Roy F. Baumeister (Ed.) Self-esteem: The puzzle of low self-regard. New York: Plenum Press, 87-116.

18 Harter, S. (1999). The construction of self. A developmental perspective. New York: The Guiford Press.

19 Lintunen, T. (1995). Self-perceptions, fitness, and exercise in early adolescence: A four-year follow-up study. Jyváskylá: University of Jyváskylá.
20 Lintunen, T. (1999). Development of self-perceptions during the school years. In Auweele, Y.; Bakker, F.; Biddle, S.; Durand, M.; Seilor, R. (Eds.) Psychology for physical educators. Champaign, Illinois: Human Kinetics, 115-134.

21 Marsh, H. W.; Hattie, J. (1996). Theoretical perspectives on the structure of self-concept. In B. Bracken (Ed.) Handbook of self-concept: Developmental, social, and clinical considerations. New York: Wiley, 38-90.

22 Marsh, H. W.; Perry, C.; Horsely, C.; Roche, L. (1995). Multidimensional self-concepts of elite athletes: How do they differ from the general population? Journal of Sport $\mathcal{E}$ Exercise Psychology 17 (1):70-83.

23 Marsh, H. W.; O’Neill, R. (1984). Self-Description Questionnaire III (SQD III): The construct validity of multidimensional self-concept ratings by late-adolescents. Journal of Educational Measurement 21:153-174.

24 Marsh, H. W.; Richards, G. E.; Barnes, J. (1986). Multidimensional self-concepts: The effect of participation in an outward bound program. Journal of Personality and Social Psychology 50 (1):195-204.

25 Matos, M. G.(1998) Comunicação e resolução de conflitos na Escola. Lisboa: Ed. FMH.

26 Matos, M. G.; Simões, C.; Carvalhosa, S. F.(2000) Desenvolvimento de competências de vida na prevenção do desajustamento pessoal e social. Lisboa: Ed. IRS.

27 Matos, M. G.; Simões, C.; Carvalhosa, S. F.; Reis, C.; Canha, L. (2000). A saúde dos adolescentes portugueses. Estudo nacional da rede europeia HBSC/OMS. Lisboa: Faculdade de Motricidade Humana.

28 Mutrie, N.; Biddle, S. J. H (1995). The effects of exercise on mental health in nonclinical populations. In S. Biddle (Ed.) European perspectives on exercise and sport psychology. Champaign, Illinois: Human Kinetics, 50-70.

29 Peixoto, F. (1996). Auto-conceito(s), auto-estima e resultados escolares: A influência da repetência no(s) auto-conceito(s) e na auto-estima de adolescentes. In M. A. Martins (Ed.) Dinâmicas Relacionais e Eficiência Educativa. Lisboa: Instituto Superior de Psicologia Aplicada, 51-69.

30 Senos, J.; Diniz, T. (1998). Auto-estima, resultados escolares e indisciplina. Estudo exploratório numa amostra de adolescentes. Análise Psicológica 16 (2): 267-276.

31 Simões, M. (2001). O interesse do auto-conceito em educação. Lisboa: Plátano.

32 Vaz Serra, A. (1988). O auto-conceito. Análise Psicológica 6 (2):101-110

33 Whitehead, J. (1995). A study of children's physical selfperceptions using an adapted physical self-perception profile questionnaire. Pediatric Exercise Science 7:132-151. 